\title{
Long-term Cost-effectiveness of Endoscopic vs Open Vein Harvest for Coronary Artery Bypass Grafting
}

\author{
Lars Oddershede ${ }^{1,2}$, Lars Holgers Ehlers ${ }^{1}$ and Jan Jesper Andreasen $2^{*}$
}

${ }^{1}$ Danish Center for Healthcare Improvements, Faculty of Social Sciences and Faculty of Health Sciences, Aalborg University, Denmark

${ }^{2}$ Departments of Cardiothoracic Surgery and Clinical Medicine, Aalborg University Hospital, Denmark

"Corresponding author: Jan Jesper Andreasen, Departments of Cardiothoracic Surgery and Clinical Medicine, Aalborg University Hospital, Hobrovej 18-22, DK-9000 Aalborg, Denmark, Tel: +45 97664651; E-mail: jja@rn.dk

Received date: March 10, 2015; Accepted date: April 10, 2015; Published date: April 13, 2015

Copyright: (c) 2015 Oddershede L, et al. This is an open-access article distributed under the terms of the Creative Commons Attribution License, which permits unrestricted use, distribution, and reproduction in any medium, provided the original author and source are credited.

\begin{abstract}
Background: The greater saphenous vein is frequently used as a conduit for coronary artery bypass grafting (CABG). Previously, veins were most often harvested using open vein harvesting $(\mathrm{OVH})$, however, endoscopic vein harvesting $(E V H)$ techniques have become increasingly popular. Nevertheless, the long-term cost-effectiveness of $\mathrm{EVH}$ remains unknown. The present study estimated the long-term cost-effectiveness of EVH versus OVH for CABG.

Methods: A Markov model was developed to estimate life-time costs (UK Pounds Sterling) and quality adjusted life-years (QALYs) with comparative results presented as incremental cost-effectiveness ratios (ICERs). Costs and probabilities of events in the $\mathrm{OVH}$ group were mainly drawn from a previously published study. Resource consumption and event probabilities in the EVH group were estimated using a meta-analysis to reflect the best available evidence. Parameter uncertainty was assessed using both one-way sensitivity analyses and probabilistic sensitivity analyses.
\end{abstract}

Results: The life-time cost/QALY was $£ 8219$ rendering EVH cost-effective compared to OVH. Sensitivity analyses showed that EVH was cost-effective in $60.4 \%$ of simulations at a threshold of $£ 30000 / Q A L Y$, reflecting a large uncertainty in the point estimate of the ICER. The main causes of uncertainty were the time-horizon and the event rates of major clinical events in the treatment groups.

Conclusions: Current evidence indicates that EVH is cost-effective for harvesting saphenous vein segments for $\mathrm{CABG}$ compared to $\mathrm{OVH}$. Further studies on long-term clinical outcomes are needed to reach a more precise costeffectiveness estimate.

Keywords: CABG; Venous grafts; Endoscopy/endoscopic procedures; Health economics; Quality of life; Postoperative care

\section{Introduction}

The short-term effectiveness and long-term safety of endoscopic vein harvesting $(\mathrm{EVH})$ versus traditional open vein harvesting $(\mathrm{OVH})$ of saphenous vein conduits for coronary artery bypass grafting $(\mathrm{CABG})$ has been investigated rigorously. Meta-analysis of the clinical evidence show that EVH is a short-term benefit as leg wound morbidity, infections, and pain is reduced without compromising the long-term safety as no differences were observed in the recurrence of chest pain, myocardial infarctions, and all-cause mortality [1-3]. Previous economic evaluations of EVH versus OVH have looked at costs and outcomes five to six weeks postoperatively $[4,5]$. Such a short time-horizon is suitable for an economic evaluation if costs and outcomes can be considered equal between treatment groups after the period in which they are compared [6]. Still, no studies have estimated the long-term (e.g. life-time) cost-effectiveness of EVH compared to $\mathrm{OVH}$ although several reviews have called for a more rigorous costeffectiveness analysis $[1,7,8]$. Therefore, the present study estimated both the short-term and the life-time cost-effectiveness of EVH of saphenous vein as a conduit for CABG using total endoscopic methods compared to OVH using a single continuous incision. This was done to provide essential information for the decision about vein harvesting method and to exemplify the importance of choosing the appropriate time horizon in cost-effective analysis.

\section{Materials and Methods}

\section{Model overview}

A decision-analytic model was developed to estimate costs and quality adjusted life-years (QALYs) from the perspective of the Danish Healthcare System. The model was constructed as a Markov model with a cycle length of three months, see Figure 1 and the figure legend for a description of the model (Figure 1). The cohort was CABG patients aged 65 years and $80 \%$ male gender. The base-case model captured life-time costs and QALYs while an alternative scenario considered costs and QALYs within three months postoperatively. All costs and QALYs accrued beyond the first year were discounted using an annual rate of $3.5 \%$ [9]. 


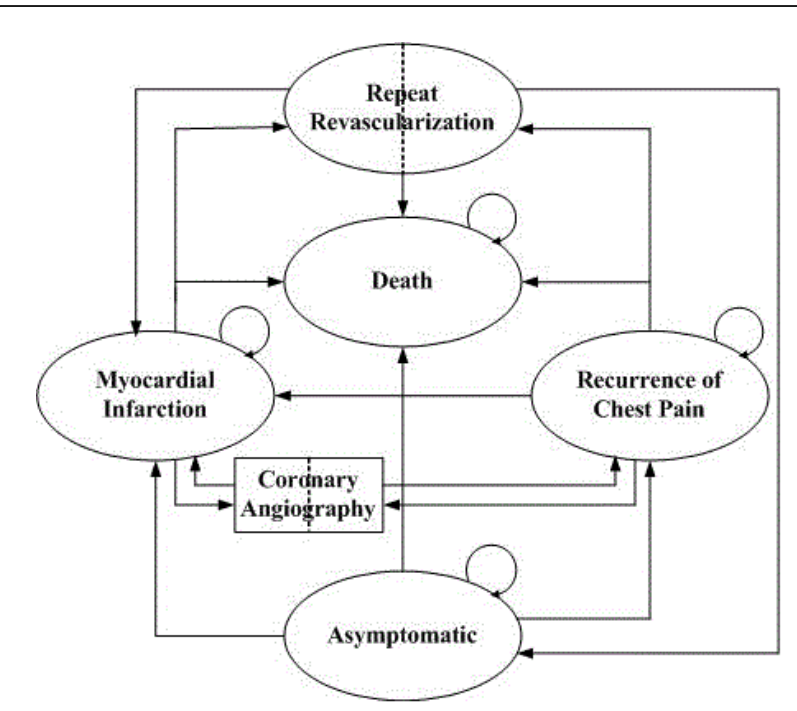

Figure 1: Structure of decision-analytic model. The postoperative course for patients treated with coronary artery bypass grafting using the saphenous vein as a conduit harvested by endoscopic or open technique is modelled in this Markov model. All patients enter the model in the health state "Asymptomatic" symbolizing that the symptoms of coronary artery disease disappeared following surgery. Cycles represent health states while boxes represent events which may occur in the health state which has an arrow leading to it. The health state "Repeat Revascularization" does not have an arrow leading back into the health state which means that patients only stay in this health state for a single cycle (three months). The stippled lines indicate that patients exit to the side where they entered.

\section{Event probabilities}

As recommended by international guidelines for cost-effectiveness analysis [10]; the estimates of treatment effectiveness are based on the formal evidence syntheses of a meta-analysis [1]. Event probabilities for the Markov model are shown in Table 1. A Danish randomized trial was used to calculate event probabilities in the OVH group [11]. Event probabilities in the EVH group were then estimated by utilizing the odds ratios and rate ratios from a meta-analysis [1]. The 95\% confidence intervals (CIs) of the odds ratios and rate ratios were utilized to estimate the parameter uncertainty. The mortality rate for the patients in the health state "Asymptomatic" was modelled using Danish life tables while patients in health states "Recurrence of Chest Pain", "Myocardial Infarction" and "Repeat Revascularization" were assumed to have a higher mortality rate [12-16]. In both treatment groups it was assumed that patients with recurrence of chest pain had a hazard ratio for all-cause mortality of 1.29 (95\% CI 0.89 to 1.87 ) compared to asymptomatic CABG patients $[12,15]$. Likewise, it was estimated that patients experiencing a myocardial infarction or a repeat revascularization had a hazard ratio for all-cause mortality of 7.82 compared to asymptomatic CABG patients $[12,16]$.

\section{QALYs}

All health states in the Markov model were assigned a health-related quality of life (HRQoL) value and the time spent in each health state was multiplied with the HRQoL value to calculate QALYs. To estimate HRQoL values for patients during the first three months postoperatively, a mapping model was utilized [17]. Pain intensity and mobility problems measured on visual analogue scales (VASs) were drawn from the best available evidence and mapped to Danish EQ-5D-3L index scores to obtain the difference in HRQoL $[1,18]$. The input for estimating short-term effectiveness, i.e. during the first cycle of the Markov model, is summarized in Table 2. In the Markov model the HRQoL values for the chronic conditions were drawn from Danish and American community based preference weights $[19,20]$. Temporary HRQoL decrements for repeat revascularization were drawn from a previous cost-effectiveness comparing CABG and stenting [21]. In the Markov model the HRQoL for health states other than "Asymptomatic" were estimated using the decrements shown in Table 3. For an example, the mean HRQoL in the health state "Myocardial Infarction" in the 20th cycle, i.e. five years postoperatively, would be $0.87-5^{\star} 0.0008-0.148=0.718$.

\section{Costs}

The mean resource consumption was combined with the unit costs to estimate the total cost per patient. The resource consumption in the OVH group was mainly estimated from a Danish randomized trial [11]. The summary statistics from a meta-analysis was used to estimate the resource consumption in the EVH group [1]. The base-case analysis assumes that surgeons are trained in $\mathrm{EVH}$ and that the wards have already purchased the video-equipment. As such, the base-case analysis views the cost of video equipment and training as sunk costs and does not include these in the analyses. To estimate the unit costs of repeat revascularizations it was assumed that $42.9 \%$ of these were performed as CABGs and the remaining as percutaneous coronary interventions. Estimates of resources consumed are summarized in Table 4.

All costs were measured in 2014 values of Danish Crowns and subsequently reported in Great British Pound Sterling ( $£ 1$ GBP $=9.16$ DKK). In the absence of information about the parameter uncertainty in unit costs an alpha and a beta were approximated assuming a standard error of $\pm 10 \%$ of the mean. Unit costs drawn from previous studies were inflated to 2014 values using a yearly inflation rate of $2 \%$. All unit costs are shown in Table 5.

\section{Analyses}

Two scenarios were constructed to investigate the cost-effectiveness of EVH compared to OVH. The two scenarios were based on two different interpretations of the long-term clinical outcomes following $\mathrm{EVH}$ and $\mathrm{OVH}$. The base-case analysis applied a Bayesian interpretation of the uncertainty in the data. This interpretation of clinical evidence is the default in health economic evaluations [22]. It entails perceiving the point estimate as our best available guess of the parameter value and the $\mathrm{CI}$ as a range which the parameter has a $95 \%$ probability of lying within. The alternative scenario assumes that the existing evidence confirms non-inferiority of EVH compared to $\mathrm{OVH}$ regarding the long-term clinical endpoint considered in Table 2. In this alternative scenario the model assumes no long-term differences in the recurrence of chest pain, myocardial infarction, repeat coronary angiography, repeat revascularization, or death; i.e. odds ratios and rate ratios presented in Table 1 are replaced by 1.00 (95\% CI: 1.0; 1.0). The alternative scenario is therefore a comparison of costs and QALYs within the first three month postoperatively. 
Citation: Oddershede L, Ehlers L, Andreasen JJ (2015) Long-term Cost-effectiveness of Endoscopic vs Open Vein Harvest for Coronary Artery Bypass Grafting. J Cardiovasc Dis Diagn 3: 195. doi:10.4172/2329-9517.1000195

Page 3 of 7

In each scenario the cost-effectiveness of EVH compared to OVH was calculated as the incremental cost-effectiveness ratio (ICER). The ICER expresses the expected additional cost of obtaining one additional QALY. To capture the uncertainty in the estimation of the ICER, one-way sensitivity analyses were conducted. The five most important parameters in the one-way sensitivity analyses were presented in Tornado diagrams. To assess the joint uncertainty in all parameters, probabilistic sensitivity analysis was conducted using second order Monte Carlo simulation. Based on the output costeffectiveness acceptability curves (CEACs) were drawn. The CEACs were used to assess the probability of EVH being cost-effective compared to $\mathrm{OVH}$ at increasing threshold values [22]. The UK threshold of $£ 30$ 000/QALY was used to assess the cost-effectiveness of EVH compared to OVH [9]. The decision-analytic model was developed in Microsoft Excel 2010 (Microsoft Corporation, Redmond, Washington, USA).

\begin{tabular}{|c|c|c|c|}
\hline Probability(transition tol transition from) & $\begin{array}{l}\text { Expected Value in OVH } \\
\text { group [Source] }\end{array}$ & Expected Value in EVH group ( $95 \% \mathrm{Cl}$ ) [Source] & Distribution \\
\hline $\mathrm{P}$ (Chest pain | Asymptomatic) until 5 years & $0.0286[28]$ & $0.0280(0.0180 ; 0.0436)[1]$ & Lognormal \\
\hline $\mathrm{P}$ (Chest pain | Asymptomatic) after 5 years & $0.0028[28]$ & $0.0028(0.0018 ; 0.0044)[1]$ & Lognormal \\
\hline $\mathrm{P}(\mathrm{MI}$ | Asymptomatic) until 0.25 years & $0.0292[29]$ & $0.0328(0.0215 ; 0.0496)[1]$ & Lognormal \\
\hline $\mathrm{P}(\mathrm{MI}$ | Asymptomatic) from $0.25-5$ years & $0.0029[15,29]$ & $0.0033(0.0022 ; 0.0051)[1]$ & Lognormal \\
\hline $\mathrm{P}(\mathrm{MI} \mid$ Asymptomatic) after 5 years & $0.0011[15]$ & $0.0012(0.0008 ; 0.0019)[1]$ & Lognormal \\
\hline $\mathrm{P}(\mathrm{MI} \mid$ Chest pain $)$ until 5 years & $0.0083[15]$ & $0.0093(0.0061 ; 0.0142)[1]$ & Lognormal \\
\hline $\mathrm{P}(\mathrm{MI} \mid$ Chest pain $)$ after 5 years & $0.0033[15]$ & $0.0037(0.0024 ; 0.0057)[1]$ & Lognormal \\
\hline $\mathrm{P}$ (Death | Asymptomatic) until 0.25 years & $0.0317[11]$ & $0.0293(0.0244 ; 0.0352)[1]$ & Lognormal \\
\hline $\mathrm{P}$ (Death | Asymptomatic) after 0.25 years & Life-table [12] & RR of all-cause mortality applied to life-table [1] & Lognormal \\
\hline $\mathrm{P}$ (Repeat Revascularization | Chest pain) & $0.0124[15]$ & $0.0150(0.0127 ; 0.0176)[1]$ & Lognormal \\
\hline $\mathrm{P}($ Repeat Revascularization | MI) & $0.0310[30]$ & $0.0373(0.0316 ; 0.0439)[1]$ & Lognormal \\
\hline $\mathrm{P}($ Coronary Angiography | Chest pain) & $0.0070[30]$ & $0.0074(0.0047 ; 0.0117)[1]$ & Lognormal \\
\hline P(Coronary Angiography | MI) & $0.0070[30]$ & $0.0074(0.0047 ; 0.0117)[1]$ & Lognormal \\
\hline
\end{tabular}

Table 1: Transition probabilities for the Markov model

\begin{tabular}{|c|c|c|c|}
\hline Quality of life outcome & $\begin{array}{l}\text { Expected Value in OVH group }(95 \% \mathrm{Cl}) \\
\text { [Source] }\end{array}$ & $\begin{array}{l}\text { Expected Value in EVH group }(95 \% \mathrm{Cl}) \\
\text { [Source] }\end{array}$ & Distribution \\
\hline \multicolumn{4}{|c|}{ Non-preference-based measures of health mapped } \\
\hline Pain on a VAS at day $5, \mathrm{~mm}$ & $28.7[17]$ & $13.9(4.2 ; 23.7)[1,17]$ & Normal \\
\hline Mobility on a VAS at day $5, \mathrm{~mm}$ & $36.0[18]$ & $12.0[18]$ & Fixed \\
\hline Pain on a VAS at day $30, \mathrm{~mm}$ & $16.1[17]$ & $13.3(10.1 ; 16.5)[1,17]$ & Normal \\
\hline Mobility on a VAS at day $30, \mathrm{~mm}$ & $30.0[18]$ & $2.0[18]$ & Fixed \\
\hline \multicolumn{4}{|c|}{ Health-related quality of life estimates for patients in the "Asymptomatic" health state } \\
\hline Baseline & $0.756(0.727 ; 0.785)[17]$ & $0.756(0.727 ; 0.785)[17]$ & Normal \\
\hline Postoperative day 5 & $0.636(0.607 ; 0.665)[17]$ & $0.685(0.655 ; 0.715)[1,17,18]$ & Normal \\
\hline Postoperative day 30 & $0.785(0.756 ; 0.815)[17]$ & $0.809(0.780 ; 0.840)[1,17,18]$ & Normal \\
\hline Three months postoperative & $0.87[31]$ & $0.87[31]$ & Fixed \\
\hline
\end{tabular}

Table 2: Health-related quality of life estimates during the first cycle of the Markov model 
Citation: Oddershede L, Ehlers L, Andreasen JJ (2015) Long-term Cost-effectiveness of Endoscopic vs Open Vein Harvest for Coronary Artery

Page 4 of 7

\begin{tabular}{|l|l|l|}
\hline Health states & $\begin{array}{l}\text { Expected Value in both group } \\
\mathbf{( 9 5 \% ~ C l ) [ S o u r c e ]}\end{array}$ & Distribution \\
\hline $\begin{array}{l}\text { Reduction for myocardial } \\
\text { infarction }\end{array}$ & $-0.148(-0.186 ;-0.109)[20]$ & Normal \\
\hline Reduction for chest pain & $-0.168(-0.205 ;-0.130)[20]$ & Normal \\
\hline Reduction per additional year & $-0.0008(-0.001 ;-0.0006)[19]$ & Normal \\
\hline $\begin{array}{l}\text { Temporary reduction for } \\
\text { repeat revascularization by } \\
\text { percutaneous coronary } \\
\text { intervention } \quad-0.04(-0.05 ;-0.03)[21]\end{array}$ & Normal \\
\hline $\begin{array}{l}\text { Temporary reduction for } \\
\text { repeat revascularization by } \\
\text { coronary artery bypass } \\
\text { grafting }\end{array}$ & $-0.09(-0.12 ;-0.07)[21]$ & Normal \\
\hline $\mathrm{Cl}=$ confidence interval & \\
\hline
\end{tabular}

Table 3: Health-related quality of life decrements used in health states of the Markov model

\begin{tabular}{|c|c|c|c|}
\hline $\begin{array}{l}\text { Type of resource } \\
\text { consumption }\end{array}$ & $\begin{array}{l}\text { Expected } \\
\text { Value in OVH } \\
\text { group[Source] }\end{array}$ & $\begin{array}{l}\text { Expected Value in EVH } \\
\text { group }(95 \% \mathrm{CI})[\text { Source }]\end{array}$ & Distribution \\
\hline $\begin{array}{l}\mathrm{P} \text { (Single } \\
\text { equipment) }\end{array}$ & 0 & 1 & Fixed \\
\hline $\begin{array}{l}\text { Duration of surgery, } \\
\text { minutes }\end{array}$ & $216[11]$ & $231(219 ; 243)[1,11]$ & Normal \\
\hline $\begin{array}{l}\text { Length of stay in } \\
\text { intensive care unit, } \\
\text { days }\end{array}$ & $2.79[1]$ & $2.84(2.57 ; 3.10)[1,11]$ & Normal \\
\hline $\begin{array}{l}\text { Length of stay in } \\
\text { ward, days }\end{array}$ & $11.5[4]$ & $11.0(10.5 ; 11.4)[1,4]$ & Normal \\
\hline $\begin{array}{l}\mathrm{P} \text { (Beside leg wound } \\
\text { revision) }\end{array}$ & $0.020[11]$ & $\begin{array}{lll}0.009 & (0.005 ; & 0.015) \\
{[1,11]}\end{array}$ & Lognormal \\
\hline $\begin{array}{l}\mathrm{P}(\text { Leg wound } \\
\text { revision in operating } \\
\text { room) }\end{array}$ & $0.010[11]$ & $\begin{array}{lll}0.004 & (0.003 ; & 0.007) \\
{[1,11]} & & \end{array}$ & Lognormal \\
\hline $\begin{array}{l}\mathrm{P}(\text { Visit from home } \\
\text { care nurse) }\end{array}$ & $0.063[11]$ & $\begin{array}{l}0.006 \\
{[1,11]}\end{array} \quad(0.003 ; \quad 0.014)$ & Lognormal \\
\hline $\begin{array}{l}\text { No. of visits per } \\
\text { patient }\end{array}$ & $7.5[11]$ & $7.5[11]$ & Fixed \\
\hline $\begin{array}{l}\mathrm{P}(\text { Visit to general } \\
\text { practitioner) }\end{array}$ & $0.143[11]$ & $\begin{array}{lll}0.046 & (0.028 ; & 0.074) \\
{[1,11]} & & \end{array}$ & Lognormal \\
\hline $\begin{array}{l}\text { No. of visits per } \\
\text { patient }\end{array}$ & $4.3[11]$ & $4.3[11]$ & Fixed \\
\hline $\begin{array}{l}\mathrm{P} \text { (Antibiotic } \\
\text { treatment) }\end{array}$ & $0.095[11]$ & $\begin{array}{l}0.026(0.020 ; 0.034)[1, \\
11]\end{array}$ & Lognormal \\
\hline $\mathrm{P}($ Readmission) & $0.016[11]$ & $\begin{array}{lll}0.010 & (0.007 ; & 0.014) \\
{[1,11]} & & \end{array}$ & Lognormal \\
\hline \multicolumn{4}{|c|}{$\begin{array}{l}\mathrm{CI}=\text { confidence interval; } \mathrm{EVH}=\text { Endoscopic vein harvesting; } \mathrm{OVH}=\text { open vein } \\
\text { harvesting; } \mathrm{P}()=\text { probability of resource being consumed }\end{array}$} \\
\hline
\end{tabular}

Table 4: Resource consumption

\begin{tabular}{|l|l|l|}
\hline Description of resource & Mean [Source] & $\begin{array}{l}\text { Distribution (Alpha; } \\
\text { Beta) }\end{array}$ \\
\hline Single use equipment & $£ 504[4]$ & Gamma (100; 5.04) \\
\hline Duration of surgery, per minute & $£ 14.6[5]$ & Gamma (100; 0.15) \\
\hline $\begin{array}{l}\text { Length of stay in intensive care } \\
\text { unit, per day }\end{array}$ & $£ 2550[32]$ & Gamma (100; 25.5) \\
\hline Length of stay in ward, per day & $£ 569[32]$ & Gamma (100; 5.69) \\
\hline $\begin{array}{l}\text { Leg wound revision without } \\
\text { general anesthesia }\end{array}$ & $£ 147[4]$ & Gamma (100; 1.47) \\
\hline $\begin{array}{l}\text { Leg wound revision in general } \\
\text { anesthesia }\end{array}$ & $£ 643[4]$ & Gamma (100; 6.43) \\
\hline Readmission & $£ 2509[33,34]$ & Gamma (100; 25.1) \\
\hline Visit from home care nurse & $£ 52.5[4,35,36]$ & Gamma (100; 0.53) \\
\hline Visit to general practitioner & $£ 41.5[37]$ & Gamma (100; 0.42) \\
\hline Course of antibiotic treatment & $£ 48.5[4]$ & Gamma (100; 0.49) \\
\hline $\begin{array}{l}\text { Transition cost to the "Myocardial } \\
\text { Infarction" state }\end{array}$ & $£ 6861[33,34]$ & Gamma (100; 68.6) \\
\hline $\begin{array}{l}\text { Transition cost to the "Coronary } \\
\text { Angiography" state }\end{array}$ & $£ 334[38]$ & Gamma (100; 3.34) \\
\hline $\begin{array}{l}\text { Transition cost to the "Repeat } \\
\text { Revascularization" state }\end{array}$ & $£ 13880[33,34]$ & Gamma (100; 139) \\
\hline Transition cost to the "Death" state & $£ 1556[33,34]$ & Gamma (100; 15.6) \\
\hline $\begin{array}{l}\text { Three month healthcare costs in } \\
\text { the "Asymptomatic" state }\end{array}$ & $£ 344[39]$ & Gamma (136; 2.35) \\
\hline $\begin{array}{l}\text { Three month healthcare costs in } \\
\text { the "Myocardial Infarction" state }\end{array}$ & $£ 939[39]$ & Gamma (17; 51.2) \\
\hline $\begin{array}{l}\text { Three month healthcare costs in } \\
\text { the "Recurrence of Chest Pain" } \\
\text { state }\end{array}$ & $£ 779[40]$ & Gamma (6.24; 125) \\
\hline
\end{tabular}

Table 5: Unit costs of resources consumed

\section{Results}

In the base-case analysis, EVH was cost-effective compared to OVH. EVH had an estimated incremental cost of $£ 1325$ per patient and an incremental effectiveness of 0.1612 QALY per patient, i.e. the ICER was $£ 8219 / \mathrm{QALY}$. The probabilistic sensitivity analysis reviled that the cost-effectiveness results from the base-case analysis contained a large uncertainty around the ICER. In the base-case analysis, EVH had a $60.4 \%$ probability of being cost-effective at $£ 30$ 000/QALY threshold. The probability of EVH being cost-effective becomes $63.2 \%$ at a threshold of $£ 100$ 000/QALY. One-way sensitivity analyses showed that the rate ratio for long-term all-cause mortality was the most important parameter for the incremental effectiveness of treatments. Likewise, the odds ratio of recurrence of chest pain was the parameter with the largest influence on the incremental cost of treatments. The remaining parameters identified as important for incremental cost and effectiveness are shown in the Tornado diagrams in Figure 2.

In the alternative scenario the ICER was $£ 93419$ /QALY and probabilistic sensitivity analysis showed a $20.2 \%$ probability of EVH 
being cost-effective at the $£ 30000 / \mathrm{Q} A L Y$ threshold. The alternative scenario showed an incremental QALY gain of 0.0048 QALY per patient within three months postoperatively. The incremental cost at three months postoperatively was $£ 444$ per patient.

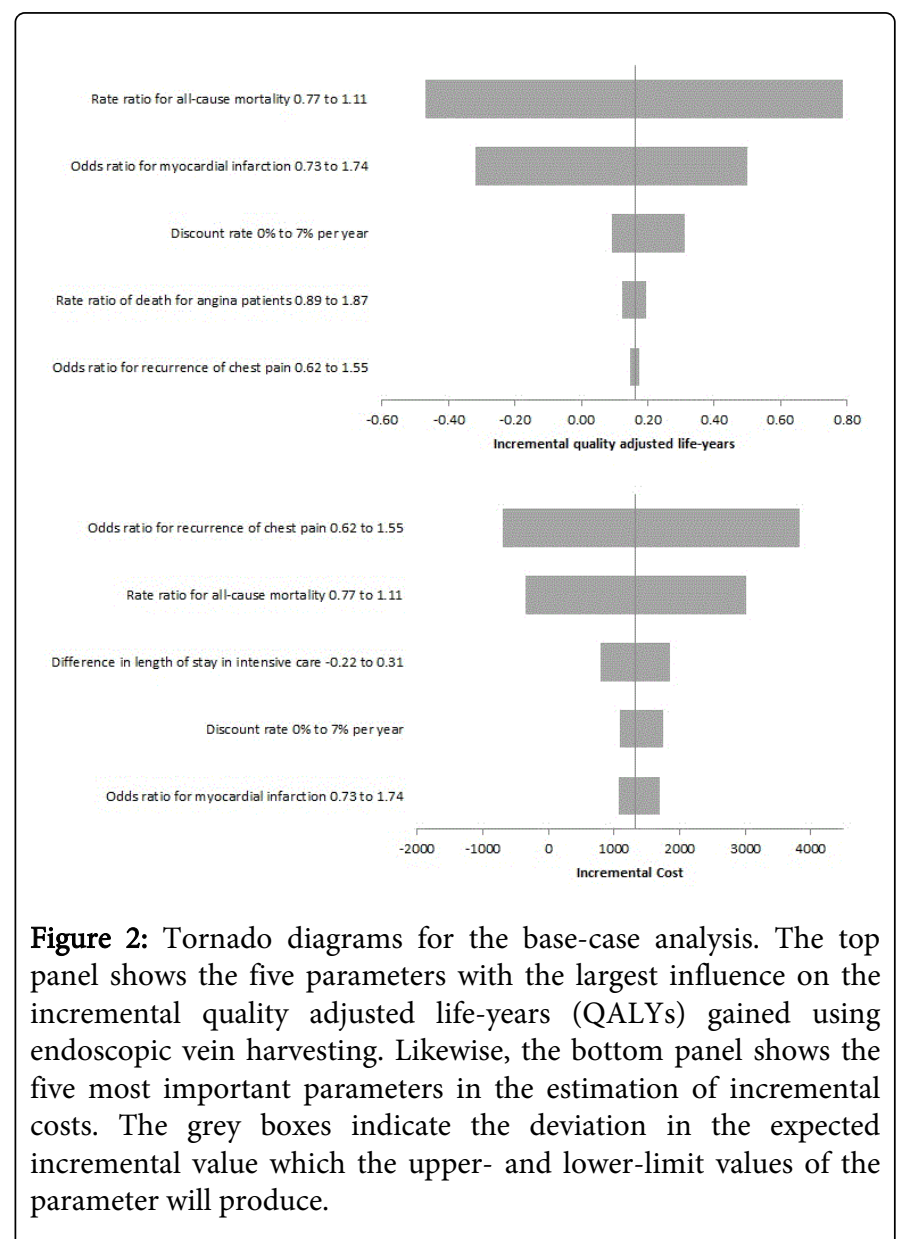

\section{Discussion}

The present study showed that EVH of saphenous vein segments for CABG was cost-effective compared to OVH. Although the economic evaluation is based on the best evidence currently available, i.e. a meta-analysis, the result is uncertain [1]. The base-case showed a large uncertainty in the cost-effectiveness result which was mainly attributed to the uncertainties in differences of long-term event-rates of major clinical event. To accommodate that some clinicians assume that the harvesting methods are completely equal in terms of longterm event-rates of major clinical events; an alternative scenario only considered costs and QALYs within three months postoperatively. Under this assumption, EVH was not cost-effective compared to $\mathrm{OVH}$. The main difference between the base-case and the alternative scenario is that the QALY gain is much larger in the base-case than in the alternative scenario. The best evidence currently available on longterm outcomes show a slight survival benefit of using EVH compared to $\mathrm{OVH}$. Although this difference is not statistically significant, the base-case applies the point-estimate as it is the current best evidence [1].
While the present study investigated the cost-effectiveness of EVH from the Danish health system's perspective, many European cardiothoracic wards might be more concerned with the question of how technologies such EVH impact their budget. We found no evidence that costs, at a departmental level, are reduced by using EVH rather than OVH. As such, EVH will increase spending at departments of cardiothoracic surgery. However, the additional money spent on EVH can be considered 'good value for money' as our analysis showed that EVH is cost-effective compared to OVH from the Danish healthcare system's perspective. To assess whether this result is transferable to other jurisdictions it is ideal to perform a formal evaluation using one of several tools to assess transferability [23-25]. It should be noted that the decision analytic model was informed with data from a meta-analysis which included published data from a variety of countries and that the results of the present economic evaluation therefore is likely to be generalizable to a number of jurisdictions.

Two studies have investigated the short-term cost-effectiveness of $\mathrm{EVH}$ or minimal invasive vein harvesting compared to $\mathrm{OVH}[4,5]$. Rao et al. performed decision analytic modeling and estimated that minimal invasive vein harvesting was cost-effective compared to conventional harvesting within six weeks postoperatively [5]. In a costeffectiveness analysis alongside a randomized trial, Oddershede et al. concluded that EVH was not cost-effective compared to $\mathrm{OVH}$ within the first five weeks postoperatively [4]. Both previous studies estimated the short-term QALY gain using mapping methods which were not based on a statistical algorithm. As such, large differences in shortterm incremental QALYs could be expected. Rao et al. estimated a gain of 0.0232 QALY within six weeks postoperatively and Oddershede et al. estimated a gain of 0.0027 QALY within five weeks postoperatively. The present study estimated the incremental QALY within three months postoperatively using a published mapping algorithm and found an incremental gain of 0.0048 QALY. These inconsistent estimates illustrate the need for trial-based investigations of short-term QALY gains. Fortunately, two forthcoming randomized controlled trials will be collecting information on HRQoL until two years postoperatively $[26,27]$.

\section{Limitations}

Although the present study is based on the current best available evidence, it would have benefitted greatly from more data on the longterm occurrence of major clinical events. The uncertainties in the odds ratios and rate ratios for occurrence of major clinical events were the main reasons for the uncertainties in incremental costs and QALYs.

In addition, the economic evaluation performed in this study did not include costs of training surgeons in the use of EVH and the cost of the video equipment. This means that the analyses inform the decision of whether a Danish ward for cardiothoracic surgery should continue to use EVH or switch back to OVH. If decision makers are interested in assessing the cost-effectiveness of changing from their current use of OVH to EVH, an additional cost of $\$ 93.21$ US dollar should be expected in the EVH group [4].

Furthermore, the present study is limited by the fact that it did not consider costs from a societal perspective. The narrow healthcare sector perspective means that potential saving for the patients on analgesics, transportation, etc. have been overlooked. More so, it is reasonable to believe that $\mathrm{EVH}$ might enable some patients to return to work a bit sooner than OVH. Any difference in productivity is not 
included in the analysis when a healthcare sector perspective is applied. It is, however, unlikely that these matters would have a large impact on the results.

Another important limitation in the present study is the fact that extrapolations had to be performed to estimate life-time costs and QALYs. One of the important implications of such extrapolations is that is based on the best current knowledge about the long-term patency of grafts harvested by EVH and OVH. Although, some studies have published results on long-term outcomes following EVH and $\mathrm{OVH}$ most were not RCTs and none had more than 5 years follow-up [1]. As such, more RCT designed to provide long-term data are needed to assess if there are equivalency patency of graft following EVH and $\mathrm{OVH}$. In addition, this will help to reduce the uncertainty in the extrapolations that must be performed. Extrapolation is a necessary evil in cost-effectiveness research and we based our assumptions on the best available evidence [1], as recommended by current guidelines for economic evaluations [10]

In conclusion, the current evidence indicates that EVH is the costeffective method for harvesting saphenous vein segments for CABG. However, if equivalency in long-term clinical outcomes between harvesting methods is assumes, EVH is unlikely to be cost-effective compared to $\mathrm{OVH}$. As such, further studies on long-term clinical outcomes are needed to reach a more precise cost-effectiveness estimate.

\section{Acknowledgement}

We wish to thank the Danish Center for Healthcare Improvements (DCHI) for funding this research. DCHI is a public, noncommercial, research organization and the authors had complete freedom of investigation in all aspects of their work.

\section{References}

1. Oddershede L, Andreasen JJ (2014) Endoscopic vein harvesting for coronary artery bypass grafting is safe and reduces postoperative resource consumption. J Cardiovasc Dis Diagn 2:171.

2. Sastry P, Rivinius R, Harvey R, Parker RA, Rahm AK, et al. (2013) The influence of endoscopic vein harvesting on outcomes after coronary bypass grafting: a meta-analysis of 267,525 patients. Eur J Cardiothorac Surg 44: 980-989.

3. Deppe AC, Liakopoulos OJ, Choi YH, Slottosch I, Kuhn EW, et al. (2013) Endoscopic vein harvesting for coronary artery bypass grafting: a systematic review with meta-analysis of 27,789 patients. J Surg Res 180 : 114-124.

4. Oddershede L, Andreasen JJ, Brocki BC, Ehlers L (2012) Economic evaluation of endoscopic versus open vein harvest for coronary artery bypass grafting. Ann Thorac Surg 93: 1174-1180.

5. Rao C, Aziz O, Deeba S, Chow A, Jones C, et al. (2008) Is minimally invasive harvesting of the great saphenous vein for coronary artery bypass surgery a cost-effective technique? J Thorac Cardiovasc Surg 135: 809-815.

6. Sculpher MJ, Claxton K, Drummond M, McCabe C (2006) Whither trialbased economic evaluation for health care decision making? Health Econ 15: 677-687.

7. Dao K 3rd, Malgor RD, Montecalvo J, Hines G (2012) Current status of endoscopic vein harvest in cardiac and peripheral vascular surgery. Cardiol Rev 20: 312-318.

8. García-Altés A, Peiró S (2011) A systematic review of cost-effectiveness evidence of endoscopic saphenous vein harvesting: is it efficient? Eur J Vasc Endovasc Surg 41: 831-836.
9. National Institute for Clinical Excellence (NICE) (2013) Guide to the methods of technology appraisal. London, $93 \mathrm{p}$.

10. Caro JJ, Briggs AH, Siebert U, Kuntz, KM (2012) Modeling Good Research Practices - Overview: A Report of the ISPOR-SMDM Modeling Good Research Practices Task Force-1. Value Heal 15: 796-803.

11. Andreasen JJ, Nekrasas V, Dethlefsen C (2008) Endoscopic vs open saphenous vein harvest for coronary artery bypass grafting: a prospective randomized trial. Eur J Cardiothorac Surg 34: 384-389.

12. Statistics Denmark. Deaths and life expectancy. http://www.dst.dk/en/ Statistik/emner/doedsfald-og-middellevetid.aspx

13. Fitzgibbon GM, Kafka HP, Leach AJ, Keon WJ, Hooper GD, et al. (1996) Coronary bypass graft fate and patient outcome: angiographic follow-up of 5,065 grafts related to survival and reoperation in ,388 patients during 25 years. J Am Coll Cardiol 28: 616-626.

14. Engebretsen KV, Friis C, Sandvik L, Tønnessen T (2009) Survival after CABG--better than predicted by EuroSCORE and equal to the general population. Scand Cardiovasc J 43: 123-128.

15. Hueb W, Lopes N, Gersh BJ, Soares PR, Ribeiro EE, et al. (2010) Tenyear follow-up survival of the Medicine, Angioplasty, or Surgery Study (MASS II): a randomized controlled clinical trial of 3 therapeutic strategies for multivessel coronary artery disease. Circulation 122: 949-957.

16. Solomon SD, Zelenkofske S, McMurray JJ, Finn PV, Velazquez E, et al. (2005) Sudden death in patients with myocardial infarction and left ventricular dysfunction, heart failure, or both. $\mathrm{N}$ Engl J Med 352: 2581-2588.

17. Oddershede L, Andreasen JJ, Ehlers L (2014) Estimation of utility values from visual analog scale measures of health in patients undergoing cardiac surgery. Clinicoecon Outcomes Res 6: 21-27.

18. Kiaii B, Moon BC, Massel D, Langlois Y, Austin TW, et al. (2002) A prospective randomized trial of endoscopic versus conventional harvesting of the saphenous vein in coronary artery bypass surgery. J Thorac Cardiovasc Surg 123:204-12.

19. Sullivan PW, Ghushchyan V (2006) Preference-Based EQ-5D index scores for chronic conditions in the United States. Med Decis Making 26: $410-420$

20. Olesen AV, Oddershede L, Ehlers L, Hvidberg MF, Petersen KD (2014) Generating a set of preference-based EQ-5D index scores for chronic conditions using a percentage-scale. Proceedings of the 10th world congress in health economics for the international Health Economics Association (iHEA)

21. Yock CA, Boothroyd DB, Owens DK, Garber AM, Hlatky MA (2003) Cost-effectiveness of bypass surgery versus stenting in patients with multivessel coronary artery disease. Am J Med 115: 382-389.

22. Briggs A, Claxton K, Sculpher M (2006) Decision Modelling for Health Economic Evaluation. (1st edn), New York, Oxford University Press

23. Drummond M, Barbieri M, Cook J, Glick HA, Lis J, et al. (2009) Transferability of economic evaluations across jurisdictions: ISPOR Good Research Practices Task Force report. Value Health 12: 409-418.

24. Goeree R, He J, O'Reilly D, Tarride JE, Xie F, et al. (2011) Transferability of health technology assessments and economic evaluations: a systematic review of approaches for assessment and application. Clinicoecon Outcomes Res 3: 89-104.

25. Welte R, Feenstra T, Jager H, Leidl R (2004) A decision chart for assessing and improving the transferability of economic evaluation results between countries. Pharmacoeconomics 22: 857-876.

26. Zenati MA, Gaziano JM, Collins JF, Biswas K, Gabany JM, et al. (2014) Choice of vein-harvest technique for coronary artery bypass grafting: rationale and design of the REGROUP trial. Clin Cardiol 37: 325-330.

27. Campanella A, Bergamasco L, Macri L, Asioli S, Devotini R, et al. (2011) Endoscopic Saphenous harvesting with an Open CO2 System (ESOS) trial for coronary artery bypass grafting surgery: study protocol for a randomized controlled trial. Trials 12:243. 
Citation: Oddershede L, Ehlers L, Andreasen JJ (2015) Long-term Cost-effectiveness of Endoscopic vs Open Vein Harvest for Coronary Artery Bypass Grafting. J Cardiovasc Dis Diagn 3: 195. doi:10.4172/2329-9517.1000195

Page 7 of 7

28. Herlitz J, Brandrup-Wognsen G, Evander MH, Caidahl K, Hartford M, et al. (2010) Symptoms of chest pain and dyspnoea during a period of 15 years after coronary artery bypass grafting. Eur J Cardiothorac Surg 37: $112-118$.

29. Kappetein AP, Feldman TE, Mack MJ, Morice MC, Holmes DR, et al (2011) Comparison of coronary bypass surgery with drug-eluting stenting for the treatment of left main and/or three-vessel disease: 3-year follow-up of the SYNTAX trial. Eur Heart J 32: 2125-2134.

30. Gupta M, Chang WC, Van de Werf F, Granger CB, Midodzi W, et al (2003) International differences in in-hospital revascularization and outcomes following acute myocardial infarction: a multilevel analysis of patients in ASSENT-2. Eur Heart J 24: 1640-1650.

31. van Stel HF, Buskens E (2006) Comparison of the SF-6D and the EQ-5D in patients with coronary heart disease. Health Qual Life Outcomes 4: 20.

32. The Capital Region of Denmark (2010) Catalogue of fees. Copenhagen, $24 \mathrm{p}$.

33. Statens Serum Institut. DRG-fees 2014 "Stationære DRG takster 2014". http://www.ssi.dk/Sundhedsdataogit/Sundhedsoekonomi/DRG-takster/ Takster\%202014.aspx
34. Statens Serum Institut. Interactive DRG 2014. Available from: http:// drgservice.ssi.dk/grouper/Modules/Home/

35. The City Council of Aarhus (2011) ABT Project 238 - appendix. Aarhus, $168 \mathrm{p}$.

36. Local Government Denmark (2011) Homecare nursing - Documentation and management. Copenhagen 44.

37. Danish Medical Association. Table of fees 2013. http://www.laeger.dk/ portal/page/portal/LAEGERDK/Laegerdk/P_L_O/Overenskomster/ Honorartabel/Honorartabel 1-4-13

38. Statens Serum Institut. DRG fees 2014 " Ambulante DAGS takster 2014". http://www.ssi.dk/Sundhedsdataogit/Sundhedsoekonomi/DRG-takster/ Takster\%202014.aspx

39. Henriksson M, Nikolic E, Ohna A, Wallentin L, Janzon M (2014) Ticagrelor treatment in patients with acute coronary syndrome is costeffective in Sweden and Denmark. Scand Cardiovasc J 48: 138-147.

40. McGillion MH, Croxford R, Watt-Watson J, Lefort S, Stevens B, et al. (2008) Cost of illness for chronic stable angina patients enrolled in a selfmanagement education trial. Can J Cardiol 24: 759-764. 